\title{
Does MTA affect fiber post retention in repaired cervical root canal perforations?
}

\section{Rodrigo Dantas PEREIRA ${ }^{(a)}$ Manoel BRITO-JÚNIOR(b) André Luis FARIA-E-SILVA(c) Karine Rodrigues GUIMARÃES(d) Laís de Oliveira MENDES(d) Carlos José SOARES(e) Manoel Damião SOUSA-NETO(a)}

(a) Universidade de São Paulo - USP, Dental School of Ribeirão Preto, Department of Restorative Dentistry, Ribeirão Preto, SP, Brazil.

(b) Universidade Estadual de Montes Claros, Department of Dentistry, Montes Claros, MG, Brazil.

(c) Universidade Federal de Sergipe, Department of Dentistry, Aracaju, SE, Brazil.

(d)Faculdades Unidas do Norte de Minas, Departament of Dentistry, Montes Claros, MG, Brazil.

(e)Universidade Federal de Uberlância - UFU, Department of Dental Materials and Restorative Dentistry, Uberlândia, MG, Brazil.

Declaration of Interests: The authors certify that they have no commercial or associative interest that represents a conflict of interest in connection with the manuscript.

\section{Corresponding Author:}

Manoel D. Sousa Neto

E-mail: sousanet@forp.usp.br

DOI: 10.1590/1807-3107BOR-2016.vol30.0083

Submitted: Jan 08, 2016

Accepted for publication: Mar 23, 2016

Last revision: Apr 25, 2016
Abstract: This study evaluated the effect of mineral trioxide aggregate (MTA) on the retention of fiber posts in repaired root canal perforations. Ten-millimeter post spaces were prepared in 60 endodontically treated bovine incisors. Root perforations were created in half of the root canals in the cervical area prior to being filled with white MTA-Angelus. Fiber posts were luted into the root canals with two self-adhesive (RelyX Unicem or Set) or self-etching (Panavia F) resin cements. The posts were submitted to a pull-out test, and the data were submitted to two-way ANOVA and Tukey's post hoc tests $(\alpha=0.05)$. The fiber posts exhibited reduced retention in MTA-repaired root canal perforations, regardless of the type of resin cement that was used $(p<0.001)$. Self-adhesive resin cements provided higher bond strength values than Panavia F, while no difference was observed between RelyX Unicem and Set $(p>0.05)$. The presence of MTA in repaired root perforations negatively affected post retention. In addition, self-adhesive cements seemed to be the best option to lute fiber posts within a root canal in these cases.

Keywords: Dental Cements; Dental Restoration Repair; Root Canal.

\section{Introduction}

Mineral trioxide aggregate (MTA), first reported in the early 1990s, ${ }_{1}^{1}$ has been widely used for perforation repair. MTA is a bioactive cement that presents satisfactory biocompatibility, antibacterial effects, proper radiopacity, and the ability to set, even in the presence of blood. ${ }^{1,2,3,4}$ In addition, the setting expansion of MTA improves the sealing of perforation margins. ${ }^{5}$ Clinically, high success rates for root perforation repairs using MTA have been reported ${ }^{6,7}$ However, the clinical success of root repair requires placement of a proper coronal restoration to reestablish aesthetics and masticatory function.

In several cases, the tooth crown is extensively destroyed, and the use of an intraradicular retainer is required. Fiber glass posts associated with composite resin are often used to restore endodontically treated teeth, ${ }^{8,9,10,11}$ which present long-term clinical success, similar to metal post-retained restorations..$^{12}$ Most failures of fiber post-retained restorations result from decementation of the retainer or fracture of the post and/or core. ${ }^{12}$ Furthermore, it has been demonstrated that an initial debonding of the luted post from the root canal increases the stress on the root and the risk of a post and/or core fracture. ${ }^{13}$

The adhesive procedures for fixing fiber posts in root canals by using multi-step resin cements are complex due to the difficulty of accessing the 
bonding substrate. ${ }^{14}$ The ability to control moisture within the root canal and to light-cure the adhesive are additional challenges. ${ }^{15}$ Thus, self-adhesive resin cements that do not require any pre-treatment with substrate are becoming more popular for cementation procedures. A recent systematic review of in vitro studies showed that use of self-adhesive resin cements may improve the retention of fiber posts in root canals. ${ }^{16}$

Although the use of MTA in managing root perforations is well established, the literature on its effect on intracanal fiber post retention is limited. Therefore, the objective of the present study was to evaluate the pull-out bond strength of fiber posts luted with different resin cements in MTA-repaired perforated root canals. The tested hypothesis was that the presence of MTA intervenes with fiber post retention in the described conditions.

\section{Methodology}

\section{Sample selection and preparation}

Sixty-three bovine incisors with mature apices and straight roots were selected for this study. Crowns were removed, and the remaining roots were standardized at a length of $15 \mathrm{~mm}$. For root canal preparation, the crown-down technique was used, with stainless steel K-files and Gates Glidden drills (Dentsply Maillefer, Ballaigues, Switzerland). The cervical and middle thirds of the canals were preflared using \#2 to \#5 Gates Glidden drills, and the apical third was prepared up to a \#50 K-file (master apical file) $1 \mathrm{~mm}$ short of the apical foramen. All enlargement procedures were carried out under irrigation with a $2.5 \%$ sodium hypochlorite $(\mathrm{NaOCl})$ solution (Biodinâmica Química e Farmacêutica Ltda., Ibiporã, PR, Brazil), while 17\% EDTA (Biodinâmica Química e Farmacêutica) was used as a final rinse for 5 minutes for the removal of the smear layer. The prepared root canals were filled with gutta-percha cones and a resin root canal sealer (Sealer 26, Dentsply, Petrópolis, Brazil) with the lateral condensation technique.

After one week, 10-mm post spaces were prepared using drills available in the fiber post kit (Exacto \#3, Angelus, Londrina, Brazil). In half of the roots, a perforation was artificially created in the buccal face, $1 \mathrm{~mm}$ from the cervical edge of the root. A \#1 spherical bur (KG Sorensen, Barueri, Brazil) was introduced at the buccal face with an inclination of approximately $45^{\circ}$ to the cervical until the root canal was reached. Then, a \#130 K-file (Dentsply Maillefer) was introduced into the perforation through the root canal until $10 \mathrm{~mm}$ of the file tip extended beyond the outer surface of the root. This last procedure resulted in a perforation with a diameter of approximately $1.5 \mathrm{~mm}$. Radiographs were taken in the mesio-distal and buccal-lingual directions to confirm the standardization of the root perforations.

\section{Perforation sealing and fiber post cementation}

In the roots with perforations, a polyester tape was positioned over the outer root surface to seal the perforation and to permit condensation of the MTA. A small cotton pellet was inserted into the root canal apical at the perforation site to prevent the blockage of the canal by the MTA. The white MTA (Angelus, Londrina, Brazil) was mixed according to the manufacturer's instructions and inserted into the perforation using an MTA carrier, followed by condensation with a hand plugger. New radiographs were taken to confirm the proper sealing of the perforation. According to the manufacturer's instructions (http: www.angelus.ind.br), the initial and final setting times of the white MTA-Angelus were 10 and 15 minutes, respectively. Thus, the MTA was allowed to set before fiber post cementation.

Then, the \#3 fiber posts (Angelus) were luted into the root canal of all roots using self-adhesive (RelyX Unicem clicker - 3M ESPE, St. Paul, MN; or Set - SDI, Bayswater, Victoria, Australia) or self-etching (Panavia F, Kuraray Co., Osaka, Japan) resin cements. All luting agents were used according to their manufacturers' recommendations. Table 1 describes the compositions of the luting agents.

\section{Pull-out test}

The roots were embedded in acrylic resin blocks to facilitate the positioning of specimens on the pull-out device coupled to a universal testing machine. The pull-out test was performed parallel to the long axis of both the post and the tooth at a cross-head speed of $0.5 \mathrm{~mm} / \mathrm{min}$ using a universal testing machine 
(DL 2000; EMIC, São José dos Pinhais, Brazil). The force that was required to dislodge each post was recorded in Newtons $(\mathrm{N})$. The experimental design is illustrated in Figure 1.

\section{Scanning electron microscopy (SEM) analysis}

For SEM analysis, three specimens with root perforations sealed with MTA were split into 2 halves and prepared according to the following protocol: immersion in $2.5 \%$ glutaraldehyde (Merck KGaA, D-64293 Darmstadt, Germany) in 0.1 M sodium cacodylate buffer at pH 7.4 (Merck KGaA, Frankfurter Str. 250, D-64293 Darmstadt, Germany) for $12 \mathrm{~h}$ at $4^{\circ} \mathrm{C}$. After fixation, the samples were rinsed with $0.1 \mathrm{M}$ sodium cacodylate buffer several times, sequentially dehydrated in an ascending ethanol (Labsynth Laboratory Products, Diadema, Brazil) series $(25 \%$ for $20 \mathrm{~min}, 50 \%$ for $20 \mathrm{~min}, 75 \%$ for $20 \mathrm{~min}, 90 \%$ for $30 \mathrm{~min}$ and $100 \%$ for $60 \mathrm{~min}$ ), immersed in hexamethyldisizilane (HMDS) (Merck KGaA, D-64293 Darmstadt, Germany) for $10 \mathrm{~min}$, placed on absorbing paper inside glass plates,

Table 1. Composition of the resin cements used in this study.

\begin{tabular}{|c|c|}
\hline Resin cement & Main components* \\
\hline \multirow[t]{2}{*}{ RelyX Unicem (self-adhesive) } & $\begin{array}{l}\text { Base paste: methacrylate monomers containing acid groups, methacrylate monomers, silanated fillers, } \\
\text { initiator components, and stabilizer. }\end{array}$ \\
\hline & Catalyst paste: methacrylate monomer, alkaline fillers, silanated fillers, and initiator components. \\
\hline Set (self-adhesive) & $\begin{array}{l}\text { Methacrylate ester phosphoric acids, urethane dimethacrylate, photoinitiator, glass of fluoride } \\
\text { aluminum silicate }[(67 \% \mathrm{w}) \text { and }(45 \% \mathrm{v})] \text { and pyrogenic silica }\end{array}$ \\
\hline \multirow{4}{*}{ Panavia $F$ (self-etching) } & $\begin{array}{l}\text { Paste A: 10-methacryloyloxydecyl hydrogen phosphate (MDP), hydrophobic and hydrophilic } \\
\text { dimethacrylate, benzoyl peroxide, camphoroquinone, colloidal silica. }\end{array}$ \\
\hline & $\begin{array}{l}\text { Paste B: sodium fluoride, hydrophobic and hydrophilic dimethacrylate, diethanol- } \pi \text {-tolvidine, } \\
\text { T-isopropylicbenzenic sodium sulfinate, barium glass, titanium dioxide, and colloidal silica. }\end{array}$ \\
\hline & $\begin{array}{l}\text { ED Primer - Primer A: 2-hydroxyethyl methacrylate (HEMA), MDP, NM- aminosalicylic acid, } \\
\text { diethanol-p-tolvidine, and water }\end{array}$ \\
\hline & $\begin{array}{l}\text { ED Primer - Primer B: NM-aminosalicylic acid, T-isopropylicbenzenic sodium sulfinate, } \\
\text { diethanol-p-tolvidine, and water }\end{array}$ \\
\hline
\end{tabular}

*As provided by the manufacturers.

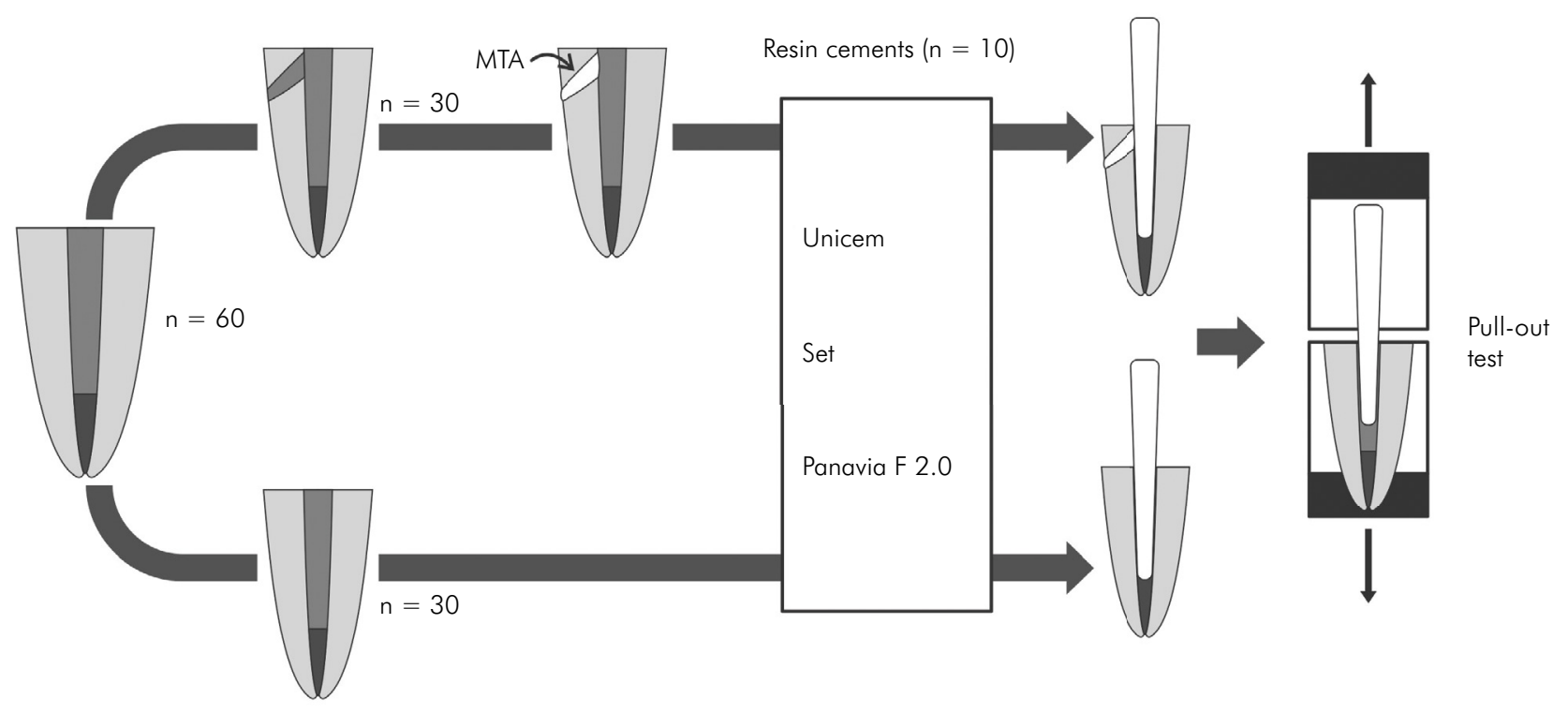

Figure 1. Experimental design. 
and left to dry in an exhaust system. Specimens were mounted on stubs with their treated surfaces face-up, sputter-coated with gold and examined under SEM (EvoMa10, Carl Zeiss, Munich, Germany) at $x 75, x 100$ and $x 500$ magnifications. The most representative areas of the sealed root perforations were photographed to identify the presence of MTA on the dentin surfaces of the root canals.

\section{Statistical analysis}

The independent variables tested in this study were "resin cement" and the "presence of MTA." Data were submitted to two-way ANOVA testing followed by Tukey's post hoc test $(\alpha=0.05)$.

\section{Results}

The results for pull-out bond strength are shown in Table 2. ANOVA showed a significant effect for the factors "resin cement" $(p<0.001)$ and "presence of MTA" ( $p$ <.001); however, the interaction between the two factors was not significant $(\mathrm{p}=0.998)$. Panavia $\mathrm{F}$ had the lowest bond strength values, while there was no significant difference between the other evaluated cements. Regardless of the resin cement used, the highest mean bond strength values were observed in the absence of an MTA-repaired perforation.

SEM analysis revealed MTA particles over the root canal walls near the perforation sites. These particles were apically concentrated in the MTA-sealed areas (Figure 2).

Table 2. Means (standard deviation) of pull-out bond strengths in Newtons.

\begin{tabular}{|c|c|c|c|c|}
\hline \multirow{2}{*}{ Resin cements } & \multicolumn{2}{|c|}{ MTA-repaired perforation } & \multirow{2}{*}{ Pooled average } & \multirow{2}{*}{$\begin{array}{c}\% \text { reduction of bonding } \\
\text { strength }\end{array}$} \\
\hline & Absent & Present & & \\
\hline Unicem & $379.9(68.5)$ & $303.9(63.2)$ & $341.0(75.05)^{\mathrm{A}}$ & $20 \%$ \\
\hline Set & $369.6(111.6)$ & $295.4(95.8)$ & $332.5(108.2)^{\mathrm{A}}$ & $21 \%$ \\
\hline Panavia $\mathrm{F}$ & $192.0(45.1)$ & $118.8(26.80)$ & $155.4(52.1)^{B}$ & $40 \%$ \\
\hline Pooled average & $312.8(116.8)^{A}$ & $239.4(108.8)^{B}$ & - & - \\
\hline
\end{tabular}

For the pooled averages, means followed by distinct letters are significantly different $(\alpha=0.05)$.

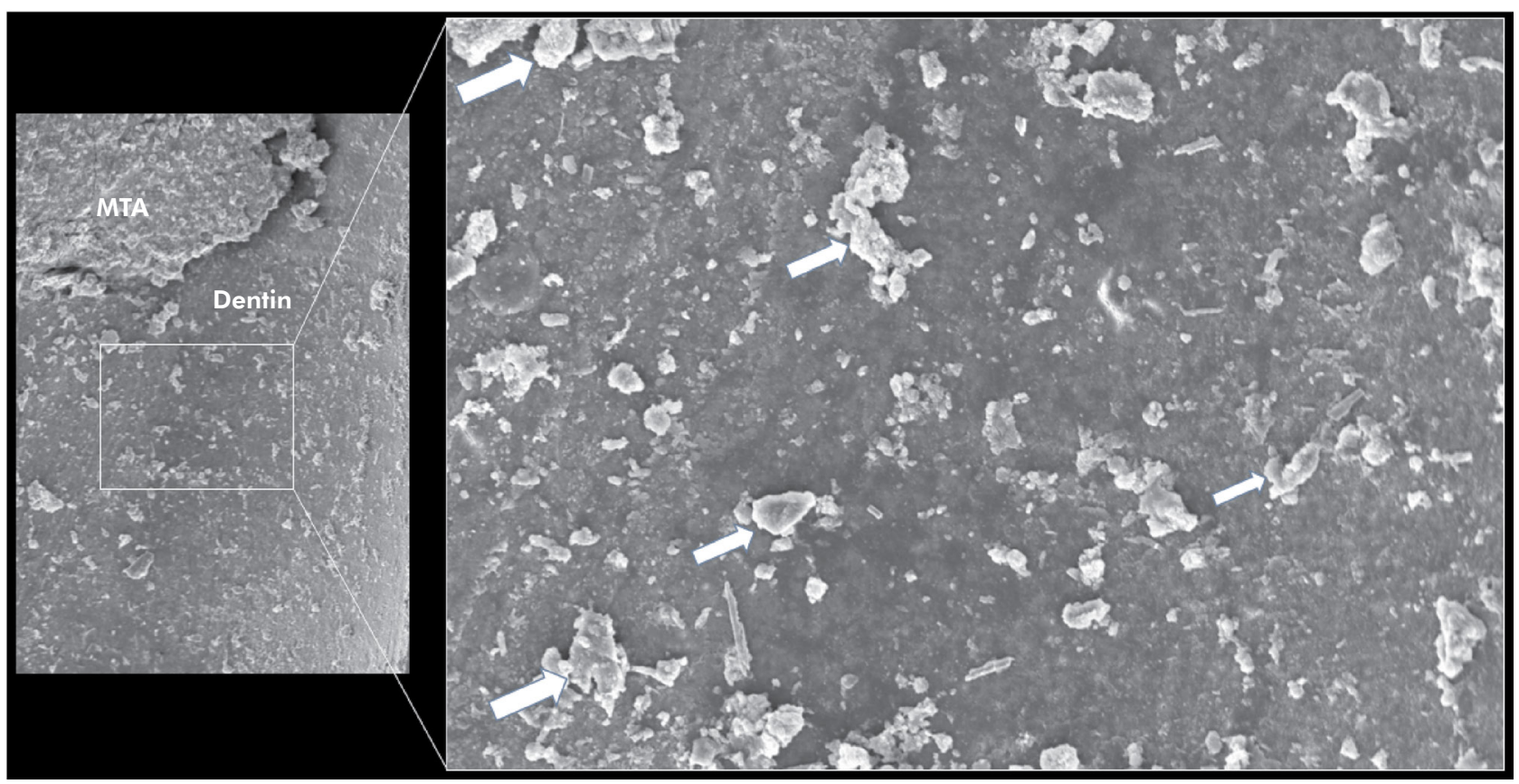

Figure 2. SEM micrographs obtained after the dehydration protocol showing the presence of MTA particles on the dentin surface of the root canal (arrows). 


\section{Discussion}

Iatrogenic perforations in the lateral walls of the root canal can occur during endodontic therapy or post-hole preparation and adversely affect the prognosis of affected teeth. ${ }^{6,15}$ Treatment of these perforations has been successfully performed with MTA by orthograde or surgical approaches. ${ }^{16,17,18}$ Even within the success of the repair procedure, however, cementation of the intraradicular post into a repaired canal may be required to permit placement of a restoration, while proper post retention favors long-term outcomes. ${ }^{11}$ In the present study, a lateral perforation located in the cervical area of the root canal was created to simulate this clinical condition and to evaluate the effect of the presence of an MTA-repaired perforation on the retention of fiber posts.

Several methodologies, such as push-out, microtensile, and pull-out approaches, have been used to evaluate the protocols of post cementation and bond strength with respect to the dentin of a root canal. ${ }^{19,20,21,22}$ In contrast to other methodologies, pull-out testing allows evaluation of the bond strength of all types of post cementation..$^{23,24}$ Thus, this methodology was chosen because the repaired perforation was located only in the cervical area of the root. The present study showed that the presence of MTA in repaired root perforations resulted in the lowest bond strength values, regardless of the luting agent used. Thus, the evaluated hypothesis was accepted.

The presence of a root perforation reduces the area of dentin available to permit the creation of a bonding interface with adhesive luting agents. A previous study showed that increasing the length of fiber post cementation into root canals improves post retention..$^{24}$ In the present study, the perforation was located in the cervical area of the root canal, the region where the highest bond strength values are observed. ${ }^{12,25}$ In addition, the contamination of the dentin adjacent to the perforation with MTA possibly had a negative effect on the retention of the fiber posts. Despite the care taken to limit placement of MTA in the perforations, areas of the dentin surface covered with this material apical to the sealed perforation sites were frequently observed in SEM images (Figure 2). Thus, reduction of the area in the cervical third of the root canal that was available to bond the luting agents to the dentin can explain these results.

In this study, post cementation was performed almost immediately after the root perforations were repaired with white MTA-Angelus, which has a short setting time. Clinically, this procedure may be advantageous for providing a permanent restoration in a single visit. ${ }^{19,20}$ However, the literature describes various initial and final setting times different from those reported by the manufacturer of the MTA-Angelus, such as 12 and $48 \mathrm{~min}^{26} 9.33$ and $23.33 \mathrm{~min},{ }^{27}$ and 18.33 and $165 \mathrm{~min} .{ }^{28}$ Thus, a high MTA setting time may require a longer time interval to achieve higher bond strength measurements of adhesive systems. ${ }^{29}$ Conversely, composite resin materials with a bonding agent placed over fresh MTA resulted in suitable interfacial bond strengths. ${ }^{30,31}$

The results of this study also revealed that self-adhesive cements presented higher bond strength values than self-etching cement. Adhesive procedures during fiber post cementation represent a challenge for clinicians, especially when etch-and-rinse adhesive systems are used in association with resin cement. In this study, a luting agent system that uses a self-etching primer was chosen due to the ease of the technique. ED Primer is less sensitive to moisture control and does not require light activation, which makes the procedure less technique sensitive. Furthermore, the chemical co-initiators of the self-etching primer increase the polymerization of Panavia F, which is primarily important in the apical third, where light activation is ineffective. ${ }^{32}$ Despite these advantages of Panavia F, the relatively low acidity of ED Primer is incapable of demineralizing the smear layer and the underlying dentin. ${ }^{33}$ Thus, low bond strength values can be expected for this luting agent, as verified in the present study.

Self-adhesive resin cements are also unable to demineralize the smear layer and the underlying dentin, interacting only superficially with the dentin tissue. ${ }^{34}$ However, the acid monomers of self-adhesive resin cements are able to chelate the calcium ions of dental tissue, which establishes a chemical bond between the cement and the dental substrate..$^{35}$ Furthermore, it has been demonstrated that self-adhesive resin cements present lower shrinkage stress than conventional 
resin cements. ${ }^{36}$ Considering that the high C-factor of the post space is critical for the development of shrinkage stress, cements with lower stress values favor maintenance of the bonding interface. These factors may explain the high fiber post retention observed when self-adhesive cements were used, corroborating the findings of several other studies. . $^{2,37,38}$

Although this study was designed to simulate a lateral root perforation at the cervical level, root perforations may be located along different thirds of the root canal. Thus, further research should investigate the intracanal retention of fiber posts in

\section{References}

1. Lee SJ, Monsef M, Torabinejad M. Sealing ability of a mineral trioxide aggregate for repair of lateral root perforations. J Endod. 1993;19(11):541-4. doi:10.1016/S0099-2399(06)81282-3

2. Holland R, Bisco Ferreira L, de Souza V, Otoboni Filho JA, Murata SS, Dezan E Jr. Reaction of the lateral periodontium of dogs' teeth to contaminated and noncontaminated perforations filled with mineral trioxide aggregate. J Endod. 2007;33(10):1192-7. doi:10.1016/j.joen.2007.07.013

3. Lovato KF, Sedgley CM. Antibacterial activity of endosequence root repair material and proroot MTA against clinical isolates of Enterococcus faecalis. J Endod. 2011;37(11):1542-6. doi:10.1016/j.joen.2011.06.022

4. Charland T, Hartwell GR, Hirschberg C, Patel R. An evaluation of setting time of mineral trioxide aggregate and EndoeSequence root repair material in the presence of human blood and minimal essential media. J Endod. 2013;39(8): 1071-2. doi:10.1016/j.joen.2013.04.041

5. Storm B, Eichmiller FC, Tordik PA, Goodell GG. Setting expansion of gray and white mineral trioxide aggregate and Portland cement. J Endod. 2008;34(1):80-2. doi:10.1016/j.joen.2007.10.006

6. Main C, Mirzayan N, Shabahang S, Torabinejad M. Repair of root perforations using mineral trioxide aggregate: a long-term study. J Endod. 2004; 30(2):80-3. doi:10.1097/00004770-200402000-00004

7. Mente J, Leo M, Panagidis D, Saure D, Pfefferle T. Treatment outcome of mineral trioxide aggregate: repair of root perforations-long-term results. J Endod. 2014;40(6):790-6. doi:10.1016/j.joen.2014.02.003

8. Bitter K, Noetzel J, Stamm O, Vaudt J, Meyer-Lueckel $\mathrm{H}$, Neumann K et al. Randomized clinical trial comparing the effects of post placement on failure rate of postendodontic restorations: preliminary results of a mean period of 32 months. J Endod. 2009;35(11):1477-82. doi:10.1016/j.joen.2009.07.026 experimental models that simulate different root canal perforations areas repaired with MTA. Furthermore, other calcium silicate cements used for root repair ${ }^{3}$ may be tested in these experimental conditions.

\section{Conclusion}

The presence of MTA in repaired cervical root canal perforations reduced the retention of fiber posts, regardless of the resin cement that was used. Furthermore, the use of self-adhesive resin cements seems to be advantageous for the luting of fiber posts within root canals in these cases.

9. Naumann M, Koelpin M, Beuer F, Meyer-Lueckel H. 10-year survival evaluation for glass-fiber-supported postendodontic restoration: a prospective observational clinical study. J Endod. 2012; 38(4):432-5. doi:10.1016/j.joen.2012.01.003

10. Santana FR, Castro CG, Simamoto-Júnior PC, Soares PV, Quagliatto PS, Estrela C et al. Influence of post system and remaining coronal tooth tissue on biomechanical behaviour of root filled molar teeth. Int Endod J. 2011; 44(5):386-94. doi:10.1111/j.1365-2591.2010.01807.x

11. Castro CG, Santana FR, Roscoe MG, Simamoto PC Jr, Santos-Filho PC, Soares CJ. Fracture resistance and mode of failure of various types of root filled teeth. Int Endod J. 2012; 45(9):840-7. doi:10.1111/j.1365-2591.2012.02041.x

12. Figueiredo FE, Martins-Filho PR, Faria-E-Silva AL. Do metal post-retained restorations result in more root fractures than fiber post-retained restorations? A systematic review and meta-analysis. J Endod. 2015;41(3):309-16. doi:10.1016/j.joen.2014.10.006

13. Santos AF, Meira JB, Tanaka CB, Xavier TA, Ballester RY, Lima RG et al. Can fiber posts increase root stresses and reduce fracture? J Dent Res. 2010; 89(6):587-91. doi:10.1177/0022034510363382

14. D'Arcangelo C, Zazzeroni S, D'Amario M, Vadini $\mathrm{M}$, De Angelis F, Trubiani $\mathrm{O}$ et al. Bond strengths of three types of fibre-reinforced post systems in various regions of root canals. Int Endod J. 2008; 41(4):322-8. doi:10.1111/j.1365-2591.2007.01367.x

15. Chersoni S, Acquaviva GL, Prati C, Ferrari M, Grandini S, Pashley DH et al. In vivo fluid movement through dentin adhesives in endodontically treated teeth. J Dent Res. 2005;19(3):223-7. doi:10.1177/154405910508400303

16. Sarkis-Onofre R, Skupien JA, Cenci MS, Moraes RR, Pereira-Cenci T. The role of resin cement on bond strength of glass-fiber posts (GFPs) luted into root canals: 
a systematic review and meta-analysis of in vitro studies. Oper Dent. 2014;39(1):E31-44. doi:10.2341/13-070-LIT

17. Tsesis I, Fuss Z. Diagnosis and treatment of accidental root perforations. Endod Topics 2006; 13(1):95-107. doi:10.1111/j.1601-1546.2006.00213.x

18. Menezes R, Silva Neto UX, Carneiro E, Letra A, Bramante $\mathrm{CM}$, Bernadinelli N. MTA repair of a supracrestal perforation: a case report. J Endod. 2005;31(3):212-4. doi:10.1097/01.don.0000137639.85637.67

19. Yildirim G, Dalci K. Treatment of lateral root perforation with mineral trioxide aggregate: a case report. Oral Surg Oral Med Oral Pathol Oral Radiol Endod. 2006; 102(5):e55-8. doi:10.1016/j.tripleo.2006.04.001

20. Ree M, Schwartz R. Management of perforations: four cases from two private practices with medium- to long-term recalls. J Endod. 2012;38(10):1422-7. doi:10.1016/j.joen.2012.06.029

21. Zaitter S, Sousa-Neto MD, Roperto RC, Silva-Sousa YT, El-Mowafy O. Microtensile bond strength of glass fiber posts cemented with self-adhesive and self-etching resin cements. J Adhes Dent. 2011;13(1):55-9. doi:10.3290/j.jad.a18396

22. Castellan CS, Santos-Filho PC, Soares PV, Soares $\mathrm{CJ}$, Cardoso PE. Measuring bond strength between fiber post and root dentin: a comparison of different tests. J Adhes Dent. 2010;12(6):477-85. doi:10.3290/j.jad.a17856

23. Faria-e-Silva AL, Mendonça AA, Garcez RM, Oliveira Ada S, Moreira AG, Moraes RR. Adhesion strategy and early bond strengths of glass-fiber posts luted into root canals. Braz Oral Res. 2012;26(5):485-7. doi:10.1590/S1806-83242012005000017

24. Faria e Silva AL, Casselli DS, Ambrosano GM, Martins LR. Effect of the adhesive application mode and fiber post translucency on the push-out bond strength to dentin. J Endod. 2007;33(9):1078-81. doi:10.1016/j.joen.2007.03.018

25. Pereira RD, Valdívia A, Bicalho AA, Franco SD, Tantbirojn $D$, Versluis A et al. Effect of photoactivation timing on the mechanical properties of resin cements and bond strength of fiberglass post to root dentin. Oper Dent. 2015;40(5):E206-21. doi:10.2341/14-115-L

26. Bortoluzzi EA, Broon NJ, Bramante CM, Felippe WT, Tanomaru Filho M, Esberard RM. The influence of calcium chloride on the setting time, solubility, disintegration, and $\mathrm{pH}$ of mineral trioxide aggregate and white Portland cement with a radiopacifier. J Endod. 2009;35(4):550-4. doi:10.1016/j.joen.2008.12.018

27. Vivan RR, Zapata RO, Zeferino MA, Bramante CM, Bernardineli N, Garcia RB et al. Evaluation of the physical and chemical properties of two commercial and three experimental root-end filling materials. Oral Surg Oral Med Oral Pathol Oral Radiol Endod. 2010;110(2):250-6. doi:10.1016/j.tripleo.2010.04.021

28. Grazziotin-Soares R, Nekoofar MH, Davies TE, Bafail

A, Alhaddar E, Hübler R et al. Effect of bismuth oxide on white mineral trioxide aggregate: chemical characterization and physical properties. Int Endod J. 2014;47(6):520-33. doi:10.1111/iej.12181

29. Atabek D, Sillelioğlu H, Olmez A. Bond strength of adhesive systems to mineral trioxide aggregate with different time intervals. J Endod. 2012;38(9):1288-92. doi:10.1016/j.joen.2012.06.004

30. Neelakantan P, Grotra D, Subbarao CV, Garcia-Godoy F. The shear bond strength of resin-based composite to white mineral trioxide aggregate. J Am Dent Assoc. 2012;143(8):e40-5. doi:10.14219/jada.archive

31. Tsujimoto M, Tsujimoto Y, Ookubo A, Shiraishi T, Watanabe I, Yamada S et al. Timing for composite resin placement on mineral trioxide aggregate. J Endod. 2013;39(9):1167-70. doi:10.1016/j.joen.2013.06.009

32. Faria-e-Silva AL, Moraes RR, Ogliari FA, Piva E, Martins LR. Panavia F: the role of the primer. J Oral Sci. 2009;51(2):255-9. doi:10.2334/josnusd.51.255

33. Wu H, Hayashi M, Okamura K, Koytchev EV, Imazato S, Tanaka $S$ et al. Effects of light penetration and smear layer removal on adhesion of post-cores to root canal dentin by self-etching adhesives. Dent Mater. 2009;25(12):1484-92. doi:10.1016/j.dental.2009.06.019

34. Monticelli F, Osorio R, Mazzitelli C, Ferrari M, Toledano M. Limited decalcification/diffusion of self-adhesive cements into dentin. J Dent Res. 2008;87(10):974-9. doi:10.1177/154405910808701012

35. Gerth HUB, Dammaschke T, Züchner H, Schäfer E. Chemical analysis and bonding reaction of RelyX Unicem and Bifix composites: a comparative study. Dent Mater. 2006;22(10):934-41. doi:10.1016/j.dental.2005.10.004

36. Frassetto A, Navarra CO, Marchesi G, Turco G, Di Lenarda R, Breschi L et al. Kinetics of polymerization and contraction stress development in self-adhesive resin cements. Dent Mater. 2012;28(9):1032-39. doi:10.1016/j.dental.2012.06.003

37. Macedo VC, Silva ALF, Martins LRM. Effect of cement type, relining procedure, and length of cementation on pull-out bond strength of fiber posts. J Endod. 2010;36(9):1543-6. doi:10.1016/j.joen.2010.04.014

38. Binus S, Koch A, Petschelt A, Berthold C. Restoration of endodontically treated teeth with major hard tissue loss: bond strength of conventionally and adhesively luted fiber-reinforced composite posts. Dent Traumatol. 2013;29(9):339-54. doi: 10.1111/edt.12013 